Thorax (1976), 31, 480.

\title{
Proceedings of The Thoracic Society
}

The Summer Meeting of The Thoracic Society was held on 15-16 July 1976 at the University of Liverpool. Summaries of the papers are given below.

\section{Pulmonary hypertension}

J. M. KAY The phenomenon of hypoxic pulmonary hypertension in man living at high altitude was first described by Rotta et al. (1956) in Peru who found that the mean pulmonary artery pressure in seven residents of Morococha $(4540 \mathrm{~m})$ was $25 \mathrm{mmHg}$ compared with a value of $12 \mathrm{mmHg}$ in residents of Lima $(152 \mathrm{~m})$. A regression equation has been devised for predicting pulmonary artery pressure at various altitudes in Latin America but there is great individual variation in the pressure found in different subjects living at the same altitude. The pulmonary artery pressure in residents of Leadville, Colorado $(3110 \mathrm{~m})$ is higher than predicted on the basis of Latin American experience and exceeds the pressure found at $3720 \mathrm{~m}$ in Peru. This is probably related to the fact that the Leadville community was established only 100 years ago, and very few families have lived there for more than two generations, whereas the Indian population of the Andes has lived at high altitude over the past 9000 years. People and animals living at high altitude have right ventricular hypertrophy and an abnormal muscularization of their pulmonary arterioles when compared with their sea level counterparts. Chronic hypoxic pulmonary hypertension and the associated pulmonary vascular changes are reversible (Abraham et al., 1971). When high altitude residents descend to sea level, the electrocardiographic signs of right ventricular hypertrophy and the pulmonary hypertension regress after several months. Pulmonary hypertension develops in animals exposed to high altitude but there is considerable species variation. Cattle are particularly susceptible and may develop right heart failure ('brisket disease') if grazed at altitudes over $2130 \mathrm{~m}$. The mechanism whereby alveolar hypoxia produces pulmonary vasoconstriction remains elusive. It is a local phenomenon since it occurs in isolated perfused lungs. Alveolar hypoxia may cause the release of a vasoconstrictor substance from a site in the lung parenchyma close to small pulmonary arteries (Kay et al., 1974).

REFERENCES

Abraham, A. S., Kay, J. M., Cole, R. B., and Pincock, A. C. (1971). Haemodynamic and pathological study of the effect of chronic hypoxia and subsequent recovery of the heart and pulmonary vasculature of the rat. Cardiovascular Research, 5, 95-102.

Kay, J. M., Waymire, J. C., and Grover, R. F. (1974). Lung mast cell hyperplasia and pulmonary histamine-forming capacity in hypoxic rats. American Journal of Physiology, 226, 178-184.

Rotta, A., Cánepa, A., Hurtado, A., Velásquez, T., and Chávez, R. (1956). Pulmonary circulation at sea level and at high altitudes. Journal of Applied Physiology, 9, 328-336.

\section{Enlargement of the carotid bodies}

PETER LAIDLER The carotid body is a chemoreceptor which responds to changes in the oxygen tension of systemic arterial blood. Arias-Stella and Valcarce $\vec{\perp}$ (1973) have described enlargement of the carotids bodies in subjects living at high altitude in theo Peruvian Andes. The cause of this enlargement iso believed to be a response of the carotid body to the chronic hypoxaemia resulting from the low baro metric pressure of the ambient air at high altitudec Edwards et al. (1971) have shown that enlargement of the carotid body also occurs at sea level in Great Britain in patients who have chronic respiratorye disease predisposing to chronic hypoxaemia.

Saldaña and his colleagues (1973) have reported from Peru that there is a 10 -fold increase in theo frequency of chemodectoma at high altitude in Perus when compared with the incidence at sea-level.

Carotid body enlargement also occurs in animalš living at high altitude and in rats subjected to simu $\frac{\mathbb{2}}{2}$ lated high altitude in a hypobaric chamber. In rats exposed to chronic hypoxia, much of the increase in? volume of the carotid bodies is due to capillary dila 3 tation. There is an increase in the volume of glomio cells in hypoxic rats, and in some rats this increase is accompanied by a hyperplasia in type I (chief) cells $\overrightarrow{7}$ As the carotid body is of neural crest embryonic? derivation, we wondered if the neurotropic carcinogenx N-ethyl-N-nitrosourea (ENU) would convert the hypoxic hyperplasia of carotid body type I cells into. neoplasia. Rats treated with combined chronic hypoxia and ENU showed enlargement of their carotid bodies but no carotid body chemodectomas occurred. Thiso finding supports the view expressed by Saldaña et al. that chemodectomas arising in high altitude natives represent the extreme degree of hyperplastic response of chemoreceptor tissue to prolonged and severe $N$ hypoxia, rather than true neoplasms.

REFERENCES

Arias-Stella, J. and Valcarcel, J. (1973). The human carotid body at high

altitudes. Pathologia et Microbiologia, 39, 292-297.
Edwards, C., Heath, D., and Harris, P. (1971). The carotid body in emphysema and left ventricular hypertrophy. Journal of Pathology,

Saldaña, M. J., Salem, L. E., and Travezan, R. (1973). High altitude黑 hypoxia and chemodectomas. Human Pathology, 4, 251-263.

\section{Pulmonary argyrophil cells}

WILLIAM TAYLOR Argyrophil cells occur in the $\stackrel{\mathbb{Q}}{\mathbb{Q}}$ bronchi and alveolar walls in the lungs of man ando 
animals. Their function and relation to pathological processes in the lung are not known. At the ultrastructural level, they contain in their cytoplasm 'dense core secretory vesicles' which are about $120 \mathrm{~nm}$ in diameter and have the typical structure of vesicles associated with the secretion of polypeptides. Argyrophil cells may occur in groups in the rabbit lung and these have been shown to have neural connections. The site, corpuscular structure, and neural connections of their 'neuro-epithelial bodies' suggest a chemoreceptor function, but the presence of the dense core secretory vesicles is consistent with an additional local hormonal action. These cells could provide an anatomical basis for the intrapulmonary chemoreception said to act in the pulmonary vasoconstrictor response to hypoxia.

The incidence of single and grouped argyrophil cells has been compared in rabbits from Cerro-dePasco in the Peruvian Andes (4330 m) with that in sea level control rabbits. The hypoxic animals from high altitude had significantly more groups of argyrophil cells in their airways (mean $10.23 / \mathrm{cm}^{2}$ ) than sea level controls (mean $5 \cdot 22 / \mathrm{cm}^{2}$ ) and significantly more individual argyrophil cells in their alveolar walls (mean 2.65/ $\mathrm{cm}^{2}$ ) than sea level controls (mean $\left.0.72 / \mathrm{cm}^{2}\right)$. These results support the theory put forward by Lauweryns and Cokelaere (1973) that pulmonary argyrophil cells are chemoreceptors which are sensitive to hypoxia.

\section{REFERENCE}

Lauweryns, J. M. and Cokelaere, M. (1973). Hypoxia-sensitive neuroepithelial bodies: intrapulmonary secretory neuroreceptors, modulated by the CNS. Zeitschrift für Zellforschung und mikroskopische Anatomie, 145, 521-540.

\section{High altitude pulmonary oedema}

PAUL H. SMITH High altitude pulmonary oedema is a condition affecting healthy individuals who ascend rapidly to altitudes exceeding $3000 \mathrm{~m}$. It is most likely to affect people indulging in physical exercise, or people native to high altitude who return home after a short stay at sea level. Hypoxia is the stimulus responsible for the condition which appears suddenly, usually within 3-48 hours after the ascent. Clinically patients develop a dry cough, dyspnoea, palpitations, nausea, vomiting, and headache. This is followed by extreme dyspnoea in which the patient coughs up a frothy, pink sputum. The condition can be fatal unless oxygen is administered or the patient is returned rapidly to a lower altitude. Cardiac catheterization shows the presence of pulmonary hypertension with a normal left atrial and pulmonary venous pressure, suggesting that there is an increased pulmonary vascular resistance in either the venous capillaries or venules.

Rats will develop pulmonary oedema when exposed to a simulated altitude equivalent to the summit of Mount Everest. When viewed under the electron microscope their pulmonary capillaries show the presence of large, fluid-filled vesicles which partially occlude the capillary lumens. These structures may be the cause of an increased capillary resistance since they should be expected to form and regress rapidly. However, their effect upon pulmonary haemodynamics lacks physiological proof, and other theories on the aetiology of high altitude pulmonary oedema, such as increased capillary permeability, left ventricular failure, changes in blood volume, and transarterial leakage, are discussed.

\section{Monge's disease}

DONALD A. HEATH and DAVID REID WILLIAMS All people living at high altitude develop features of acclimatization to chronic hypoxia which may be functional or structural in nature. Although they have pulmonary hypertension, they lead active lives, and thriving communities exist above $4000 \mathrm{~m}$. A minority of subjects living in the Andes, however, develop a complex clinical picture composed of cardiovascular, respiratory, haematological, and neurological elements. This syndrome is referred to as 'Monge's disease' (Monge, 1928) or 'chronic mountain sickness'. The basis of the condition is that the hyperventilation of acclimatization is replaced by hypoventilation. This exaggerates alveolar hypoxia, lowers still further the already diminished arterial oxygen saturation, and leads to haemoglobin levels exceeding $23 \mathrm{~g} / \mathrm{dl}$. Pulmonary hypertension increases. There is clubbing of the fingers and haemorrhages develop beneath the fingernails. The condition may prove fatal unless the subject moves to a lower altitude when all the clinical features undergo rapid reversal (Heath and Williams, 1976). The cause of the hypoventilation is obscure. Insufficient pathological evidence has been brought forward to support the concept of Monge's disease as a distinct pathological entity. Three clinicopathological forms have been postulated by Arias-Stella et al. (1973). They are 'chronic soroche' (chronic lack of acclimatization), 'secondary chronic mountain sickness' (where a disease giving rise to chronic hypoxia complicates the mountain environment), and 'true Monge's disease' (idiopathic hypoventilation developing at high altitude).

\section{REFERENCES}

Arias-Stella, J., Krüger, H., and Recavarren, S. (1973). Pathology of chronic mountain sickness. Thorax, 28, 701-708.

Heath, D. and Williams, D. R. (1976). Man at High Altitude. Churchill Livingstone, Edinburgh.

Monge, M. C. (1928). La enfermedad de los Andes; sindromes eritrémicos. Anales de la Facultad de Medicina de Lima, 11, 314.

Superior lung function of Jamaican children in a hill-farming community as compared with their urban compatriots

G. J. MILlER, M. J. SAUNDERS, R. J. C. GILSON, and M. T. ASHCROFT Forced expiratory volume in one second and forced vital capacity were measured in 622 children in urban and rural Jamaica. The rural children belonged to hill-farming communities and were considered to be physically more active than 
urban children. Lung volumes (by helium dilution), indices of gas transfer, and the responses to progressive submaximal exercise were assessed in 54 urban and 54 rural children of African ethnic origin believed to be of common genetic stock. After allowance for differences in sitting-height, forced vital capacity averaged $8 \%$ greater in boys than girls, $15 \%$ greater in children of European origin than those of African descent, and $5 \%$ greater in rural children than urban children. Residual volume was larger in boys than in girls but showed no differences between localities. The rate of increase of total lung capacity and the singlebreath carbon monoxide transfer factor with height was greater in the rural children than in the urban children.

Rural children had on average a larger fat-free mass than urban children, together with a greater chest circumference at standard height and subscapular skinfold thickness. These differences, together with a better exercise performance, were consistent with an increased habitual vigorous activity in hill-children. Differences in vital capacity and total lung capacity between sexes and between localities disappeared when allowances were made for body size and standardizedexercise cardiac frequency.

Lung volumes and gas transfer appear to increase with increasing habitual vigorous activity during childhood. Regression relationships are presented which summarize the relationships of lung function to body size, ethnic composition, sex, and exercise performance.

\section{A study of the prognostic relevance and repeatability of 'sensitive' tests of lung function}

M. K. BENSON, C. M. FLETCHER, N. B. PRIDE, and S. F. TATTERSALL An eight-year prospective study of 800 working men has indicated that in middle age those smokers who are likely to become disabled by airflow obstruction must already have a reduction in forced expired volume (FEV). To test the prognostic validity and repeatability of some other indices of chronic airway disease, measurements of 'closing volume', expiratory flow at $50 \%$ and $25 \%$, total lung capacity, expiratory $\mathrm{N}_{2}$ slope, $\mathrm{PaO}_{2}$, and $\mathrm{KcO}$ were made on 400 male smokers and 90 non-smokers aged 20-29 and $40-54$, and correlations between these tests and FEV were examined. Repeatability of the tests was studied by repeat measurements on 320 of the men after one year.

The results indicate that none/some of the tests are indicators of chronic airflow obstruction but only some of them are repeatable enough to be of practical use.

Use of respiratory function tests in diagnosis and management of patients with airway obstruction between the mouth and carina

B. D. W. HARRISON In 16 patients with upper airway obstruction breathlessness was a symptom in those with maximum mid vital capacity flows in inspiration or expiration of 1.7 litres per second or less, and all but one of these had stridor (inspiratory in 7, expira을 tory in one, and both inspiratory and expiratory in 2)흐

The ratio $\mathrm{FEV}_{1} / \mathrm{PEF}$ (Empey, 1972; Cotes, 1975) did not help in separating patients with upper airway, obstruction from normal subjects or from patients with lower airway obstruction, and three reasons fof this are advanced.

Two patients had tracheal stenosis in the region of the suprasternal notch. Each showed a twin-humpedw expiratory flow volume curve, and in one patient the stenosis was demonstrated both physiologically ance radiologically to move in and out of the thorax. The importance of a standard posture during seria measurements is emphasized.

In patients with extrathoracic airway obstruction总 inspiratory flow was generally more impaired tharo expiratory, and the ratios MMEF : MMIF (Miller and Hyatt, 1973) obtained from flow vclume loops, and FEV $_{1}$ : FIV, (Clark, 1970) obtained from force spirograms provided the most helpful separation frome normal subjects. In this group of patients pulmonaris function tests were of greatest value in (1) followin $\overrightarrow{\mathrm{go}}$ the progression of the disease and the response to therapy, where serial measurements of inspiratory flows were most useful; and (2) those patients witto both extrathoracic obstruction and diffuse intrapul monary airway obstruction, where the flow volumb loop was most useful.

Two patients were initially treated for asthma and presented considerable clinical diagnostic problems Flow volume loops showed a low-flow expiratore plateau diagnostic of severe intrathoracic airway ob? struction in the absence of the clinical or radiological features of severe emphysema. This combination sug. gested intrathoracic tracheal obstruction which wast confirmed by tracheal tomography.

REFERENCES

Clark, T. J. H. (1970). Inspiratory obstruction. British Medical Journa 3, 682 .

Cotes, J. E. (1975). Lung Function, 3rd ed., p. 94. Blackwell Publications Empey, D. W. (1972). Assessment of upper airways obstruction British Medical Journal, 3, 503.

Miller, R. D. and Hyatt, R. E. (1973). Evaluation of obstructing lesions of the trachea and larynx by flow volume loops. American Review of Respiratory Disease, 108, 475.

\section{Response to oral and inhaled steroids in patients witb chronic airways obstruction}

S. FREEDMAN, D. K. SURI, and S. M. HARDING Previous trials of oral steroids in patients with chronic bronchitis and airways obstruction have shown that onl a minority achieve a significant improvement in vente latory capacity. We have carried out two trials of steroid aerosol (betamethasone valerate) in such patients, comparing its effect with that of predniso lone. The patients all had a history of chronic produce tive cough, $\mathrm{FEV}_{1.0}$ less than $70 \%$ of predicted norma in the absence of any other cardiac or pulmonarm disease, and had not previously had any steroiğ 
therapy. We excluded patients with a history of episodic or seasonal breathlessness with wheezing. The two trials involved 18 inpatients and 18 outpatients respectively; of these, 15 had a family history of asthma or allergic disease, five had blood eosinophilia, eight sputum eosinophilia, and 14 one or more positive skin tests. Both studies involved three consecutive treatment periods, the first with placebo aerosol, the second with active aerosol ( $800 \mu \mathrm{g} /$ day), and the third with oral prednisolone (30 $\mathrm{mg} / \mathrm{day})$. Twice daily measurements of $\mathrm{FEV}_{1.0}$ and FVC, before and after $160 \mu \mathrm{g}$ isoprenaline by aerosol, and daily sputum volumes were recorded for the inpatients; three patients had significant increases in $\mathrm{FEV}_{1.0}$ on the steroid aerosol, ranging from $61 \%$ to $190 \%$ but neither they nor the remaining 15 had any significant further improvement with oral prednisolone. In the outpatients, assessment was by means of a diary card of symptoms and twice daily Airflometer readings. Three patients showed significant response to oral prednisolone but lesser response to the aerosol. We were unable to pick out any characteristic which distinguished the six responders from the remainder but conclude that, in view of the lack of systemic effects, therapeutic trials of steroid aerosols have a place in the assessment of patients with chronic airways obstruction.

\section{HLA antigens in diffuse fibrosing alveolitis}

c. c. EVANS Diffuse fibrosing alveolitis is a condition of unknown aetiology. Among several possible theories of causation genetic factors may play a part and there are many familial instances of the disorder (Hughes, 1964).

HLA antiben determinations are currently highlighting genetic factors in many disorders (Svejgaard et al., 1975) and such tissue typing using the standard two-stage microlymphocytotoxic technique has been performed on 20 Caucasian subjects with diffuse fibrosing alveolitis. All patients were breathless on exertion, had basal end-inspiratory crepitations, and radiographic evidence of pulmonary fibrosis often with honeycombing and usually with a basal preponderance. The fibrosis could not be attributed to any external provoking agent nor was it associated with any systemic disorder.

Spirometry and static lung volumes and the singlebreath transfer factor were measured. Rose Waaler rheumatoid factor and antinuclear antibody were determined. Lung biopsy was consistent with the diagnosis in five patients.

All subjects had impaired gas transfer (mean TLco $46.2 \%$ predicted) and all but one showed a restrictive ventilatory disorder (VC 70\% and FEV $71 \%$ predicted). RA was present in $30 \%$ and ANA in $25 \%$. HLA 12, a second series antigen, was found in 16 $(80 \%)$ of the subjects whereas the frequency of this antigen in the control population is approximately $30 \%(P<0.001)$.
Familial studies further suggest that a gene located on chromosome 6 close to the locus for HLA 12 is an important factor in the genesis of pulmonary fibrosis.

REFERENCES

Hughes, E. W. (1964). Familial interstitial pulmonary fibrosis. Thorax, 19, 515-524.

Svejgaard, A., Platz, P., Ryder, L. P., Nielsen, S., and Thomsen, N. (1975). HLA and disease associations-a survey. Transplantation Reviews, 22, 3-43.

\section{Trephine biopsy of the lung in the management of cryptogenic fibrosing alveolitis}

P. H. WRIGHT, S. J. STEEL, and B. E. HEARD Cases submitted for diagnostic trephine biopsy at the London Chest and Brompton Hospitals were reviewed. In 57 a diagnosis of cryptogenic fibrosing alveolitis was made. None of these cases had signs or symptoms of a systemic disorder, and cases giving a history of exposure to known causes of extrinsic allergic alveolitis were excluded. The biopsy specimens were reviewed and graded according to the degree of increase of fibrous tissue, intra-alveolar cells, and interstitial cells in conjunction with a pathologist who had no clinical details of the cases. Respiratory function tests had been carried out on most of the patients immediately before biopsy: these usually consisted of spirometry and determination of the single-breath carbon monoxide transfer factor by resparameter. Chest radiographs were taken of all the patients at the time of biopsy, and all were abnormal. They were graded according to the UICC Cincinnati classification for pneumoconioses by a member of the British National Panel who had no details of the cases. Details of the follow-up of the patients were obtained from the referring chest physicians and were available for all except one case who had emigrated. These consisted of review of their clinical and radiological progress. The clinicians were asked to assess the response to corticosteroids, if these had been given. A statistical analysis is presented of the correlations between these data with reference to the use of the trephine biopsy of the lung to forecast progress, and response to corticosteroids.

\section{Role of transbronchial biopsy}

D. E. STABLEFORTH Transbronchial biopsy (TBB) of diffuse or localized lung infiltrates and solid peripheral tumours is a safe technique when performed through the flexible fibreoptic bronchoscope. It was carried out on 69 patients between 18 and 76 years of age, occasionally with fluoroscopic guidance. Lung or tumour tissue was obtained in $62(89 \%)$ and proved of diagnostic value in $19(28 \%)$. Of 18 patients with suspected pulmonary sarcoidosis, six had positive TBBs, and lung so obtained was the sole histological basis for diagnosis in three. 
Biopsy was positive in four of 10 cases of primary or locally recurrent peripheral bronchial carcinoma. Previously undiagnosed focal $x$-ray shadowing was shown to be organizing or resolving pneumonia in five cases and pulmonary tuberculosis in another. Fibrosing alveolitis was identified in three, extrinsic allergic alveolitis in one, and simple pneumoconiosis in one, using this technique.

Minor haemoptysis occurred on five $(7 \cdot 3 \%)$ occasions and pneumothorax once $(1.4 \%)$ in 69 patients biopsied. There were no other complications or deaths. While diagnostic tissue is obtained somewhat less of ten by TBB than by the available percutaneous needle biopsy techniques at the present time, the morbidity is substantially lower when the transbronchial route is used.

TBB has enabled a tissue diagnosis to be made in severely ill or hypoxaemic patients and in those undergoing assisted ventilation, in whom more hazardous techniques would certainly not have been justifiable.

\section{Whole-body potassium in chronic airway obstruction}

A. D. HOWIE, A. I. PACK, K. BODDY, MAUREEN MAHAFFEY, and F. MORAN Studies of body electrolyte composition in patients suffering from chronic airway obstruction have suggested that gross potassium depletion can occur. These studies have been confined to the measurement of exchangeable potassium $(\mathrm{Ke})$ by the technique of isotope dilution following the administration of potassium $-42\left({ }^{42} \mathrm{~K}\right.$ ) (Schloerb et al., 1970; Campbell et al., 1975). The interpretation of the results obtained by the isotope dilution technique is dependent on equilibration having been reached between the administered radioactive isotope and the native potassium.

The present study was designed to measure wholebody potassium in 10 patients with chronic cor pulmonale by estimating the activity of potassium- -40 , a naturally occurring radioisotope in a whole-body monitor. By using this technique the problem of equilibration was avoided.

In all patients the whole-body potassium was not significantly less than that predicted from height and age. It is suggested that the apparent disparity between whole-body potassium and exchangeable potassium could be explained by the requirement for a longer equilibration period when using isotope dilution techniques in patients who are in a chronic hypoxaemic state.

\section{REFERENCES}

Campbell, R. H. A., Brand, Hilary, L., Cox, J. R., and Howard, P. (1975). Body weight and body water in chronic cor pulmonale. Clinical Science and Molecular Medicine, 49, 233.

Schloerb, P. R., King, C. R., Kerby, G., and Ruth, W. E. (1970). Potassium depletion in patients with chronic respiratory failure. American Review of Respiratory Disease, 102, 53.
Antibiotic policy for bacterial infections complicating thoracic and other injuries

S. T. ATHERTON, D. M. WRIGHT, D. J. White, and SHERWOOD JONES Patients with multiple injurie especially those requiring prolonged ventilator treas ment, are susceptible to colonization and subsequeat infection by pathogenic bacteria; this infection caff kill the patient (Ambiavagar et al., 1966). The dilemma facing the clinician is when to start antibiotic therapy. Antibiotics given prophylactically increase the death rate and morbidity of susceptible patients (Price an Sleigh, 1970). On the other hand, if antibiotics ary given when the signs of endotoxaemia are evident they are frequently ineffective. For example, in this unit four patients with multiple injuries died from Gram-negative endotoxaemia; antibiotics were started only when signs of endotoxaemia appeared. Retrø spective studies showed that in each case a rapid ris in temperature, white cell count or blood glucose preceded the clinical signs of endotoxaemia by one ox two days. These observations were next incorporated into an antibiotic policy which was tried out ove्e the following two years on 16 patients with multiple injuries. In this group two of the six deaths were duf to endotoxaemia, a result which suggests that the antibiotic policy benefited the patients.

REFERENCES

Ambiavagar, M., Robinson, J. S., Morrison, I. M., and Jones, E. (1966). Intermittent positive pressure ventilation in the treatment of severe crushing injuries of the chest. Thorax, 21, 359-366.

Price, D. J. E. and Sleigh, J. D. (1970). Control of infection due Klebsiella aerogenes in a neurosurgical unit by withdrawal of all antibiotics. Lancet, 2, 1213-1215.

M. tuberculosis resistance to rifampicin and etham butol: a clinical survey

J. B. MACDONALD In an effort to assess the medicaf and social interrelationships producing drug resistance? cultures of $M$. tuberculosis referred to the Tuberculo sis Reference Laboratory, Cardiff in the perio $\Phi$ 1972-73 were assessed for resistance to rifampicin or ethambutol. Ninty-seven cases were found. Resistance to either drug was equally common. Cultures tended t $\overline{\bar{\sigma}}$ be either fully sensitive or highly resistant to rifampicirfo whereas ethambutol resistance in many cases developed in a stepwise fashion. Detailed case notes were obtained on 84 subjects $(88 \%)$ and no cases off primary resistance were found. Men outnumbere $\mathbb{Q}$ women by over $3: 1$. Surprisingly, most patients were born within the British Isles and only four subject originated in the Indian subcontinent. The majorite? of patients had received rifampicin or ethambutol in 'reserve' regimens, had had tuberculosis for more thaw 10 years, came from lower social classes, tended tō drink and smoke heavily, and had severe socia? problems. 
It is commonly thought that the emergence of drug resistance is primarily the fault of the patient. It was salutary to discover that more than half these subjects had been prescribed unacceptable regimens containing rifampicin or ethambutol by their physicians. Where these drugs were used in a 'reserve' regimen the initial therapy had been acceptable in only $29 \%$ of patients. Sensitivity testing was rarely done, and in many instances the results were ignored.

A small minority of patients were considered fully cooperative. Physicians seemed relatively unaware of cooperation failure, and few made any attempt to improve cooperation. An overall subjective assessment put the responsibility for the acquisition of drug resistance at $65 \%$ patient: $35 \%$ doctor, medical error taking at least half the responsibility in $40 \%$ of cases.

\section{Diagnosis of pleural effusion}

J. A. EVANS, C. D. ERAUT, and M. CAPLIN Several large series of patients with pleural effusion with attempts to separate transudates from exudates have been reported (Light et al., 1972); Chandrasekhar et al., 1969). Less attention, however, has been paid to methods of histological and causal diagnosis.

We present the results of a prospective study of the cases of 50 consecutive patients with pleural effusion. All the patients were admitted from the Chest Clinic to the London Chest Hospital and subjected to a standard series of tests, and further special investigations were performed if required. We wished to find the histological and causal diagnosis and assess the efficacy of each of the tests in this.

A histological or causal diagnosis was made in $37(74 \%)$. Of the 50 effusions, $18(36 \%)$ were malignant, $12(24 \%)$ were tuberculous, and seven (14\%) were due to miscellaneous causes. In 13 further cases $(26 \%)$, the diagnosis remained unknown. Of the 37 cases, pleural biopsy was diagnostic in $16(40 \%)$. In the remaining 21 cases $(60 \%)$, a diagnosis was made from a combination of methods, as will be discussed. Pleural biopsy was attempted in 45 cases, and pleura. was obtained in 40 . Thoracoscopy and biopsy was performed in nine cases, and a histological diagnosis was: obtained in two of these.

The separation of the effusions into transudates and exudates was not possible, nor would it have helped. In the 13 cases where no diagnosis was made, the, effusions were small. A scheme for the diagnosis of pleural effusion is suggested.

\section{REFERENCES}

Chandrasekhar, A. J., Palateo, A., and Dubin, A. (1969). Archives of Internal Medicine, 123, 48-50.

Light, R. W., MacGregor, M. I., Luchsinger, P. C., and Ball, W. C. (1972). Annals of Internal Medicine, 77, 507-513.

\section{Diagnostic retrieval from thoracoscopy}

J. R. PEPPER The aetiology of a pleural effusion is often unknown when a patient leaves hospital. In an attempt to remedy this and to avoid unnecessary open pleural biopsies, an alternative method of thoracoscopy has been devised. The method also enables intrapleural tumours to be diagnosed. A trocar and cannula, which are oval in cross-section, have been used. This allows the simultaneous passage of a thoracoscope and biopsy forceps.

A retrospective review of 36 patients $(28$ males, 8 females) with an age range of 14-77, mean 55 years, has been done. A diagnosis was made in 29 patients. Of these, 17 were malignancies, five mesotheliomas, eight adenocarcinomas, one oat-cell carcinoma, one reticulum-cell sarcoma, and two metastases from carcinoma of the breast. Of the remainder, six were infective: three tuberculosis, one $E$. coli, and two sterile post-pneumonic. The remaining six patients comprised two lipomas, two cysts (one bronchogenic, one pleuropericardial), one congestive cardiac failure, and one post-traumatic haematoma. Seven patients remain undiagnosed, two of whom have subsequently died from unrelated causes. Two patients were eventually found to have malignancies, one mesothelioma and one metastatic adenocarcinoma.

Of the 17 malignancies, 16 had negative pleural cytology, 17 had negative sputum cytology, and 15 had negative pleural needle biopsies, six of whom had more than one biopsy. Thoracoscopy enabled a diagnosis to be made in 29 out of 36 cases $(80 \%)$. A strong case can therefore be made for performing thoracoscopy and biopsy early in the investigation of a pleural effusion or intrapleural tumour.

\section{Malignant pleural effusions}

H. R. S. HARLEY Forty-four patients with malignant pleural effusions, treated by talc pleurodesis, were analysed. The following conclusions were drawn.

1. Cancer of the lung is much more likely to give rise to a malignant pleural effusion in women than in men. 2. In the case of cancer of the lung adenocarcinoma is particularly liable to cause malignant pleural effusion.

3. Adenocarcinoma appears to have a special tendency to disseminate cells into pleural effusions, whereas squamous-cell tumours and sarcoma, other than the lympholeukaemia group, have little tendency to do so. Oat-cell tumours are intermediate in this respect.

4. The large majority of malignant pleural effusions in men are caused by cancer of the lung, whereas in women extrathoracic cancers are at least as frequent. 5. Bilateral malignant pleural effusions are more of ten caused by extrathoracic cancers than by cancer of the lung.

6. Pleural effusions in cancer patients may or may not be due directly to the tumour, and may or may not be malignant. The recognition of non-malignant effusions is important, especially when of the exudative type. Such may be caused by obstructive pneumonitis, pulmonary infarction, or radiation injury of the lymphatic drainage. 
7. Malignant effusions are exudates, they may or may not be bloodstained, and they may or may not contain malignant cells, according to their causation and to the histopathology of the tumour.

8. Diagnosis can be made in a high percentage of cases by exfoliative cytology and tissue biopsy. It was established by these methods in $75 \%$ of patients in the present series.

9. The pathogenesis of malignant pleural effusions is variable. In my opinion, most are due to lymphatic obstruction, some are due to direct or metastatic involvement of the pleura, and a very few may be due to superior vena caval obstruction. Pleural metastases may occur without effusions and effusions without metastases. The presence of pleural metastases does not exclude mediastinal lymphatic obstruction as the cause of the effusion.

10. Before treating a pleural effusion in a cancer patient a full assessment must be made of its causation, the disability resulting from it, and the general condition of the patient. Non-malignant causes should be corrected.

11. Malignant effusions which reaccumulate rapidly and embarrass respiration should be treated by intercostal talc pleurodesis using two cannulae, unless the disease is terminal. The effusion can be eliminated or controlled in $90 \%$ of patients by this technique, whatever the pathogenesis, and wherever the primary tumour may be. This method is simple, effective, and non-toxic; it causes negligible damage to the lung, and it rarely needs to be repeated. Thoracotomy in asscciation with talc is rarely required.

\section{Neurological damage after open-heart surgery}

M. A. BRANTHWAITE A modified electroencephalograph or cerebral function monitor has been used to identify the timing of neurological insults during cardiac surgery. There is a high incidence of sudden change at the onset of bypass, and alterations suggestive of cerebral depression are associated with significantly greater falls in systemic arterial blood pressure. Use of a modified thermovelocity technique has demonstrated that the cerebral blood flow falls at the onset of bypass if hypotension occurs, even when the overall flow rate from the extracorporeal apparatus is high. Microemboli from the perfusion system may also contribute to cerebral damage at the onset of perfusion; there has been a highly significant decrease in the incidence of neurological damage following the introduction of small-pore filters on the arterial line, together with prophylactic use of vasopressor agents given when hypotension is a prominent feature of the early stages of cardiopulmonary bypass.

\section{Changes in memory function after open-heart surgery}

D. W. BETHUNE The results given in the literature describing the patterns of mortality and morbidity after open-heart surgery suggest a rapidly changi高 prognosis for these patients. In order to follow the postoperative course in detail we have used a battefy of psychometric tests. We have found significafit changes in memory retention in the majority $\overline{\mathbb{f}^{\prime}}$ patients after open-heart surgery with the use of bubble oxygenators during bypass.

Similar though smaller changes are also seen in patients following anaesthesia and surgery when cardiopulmonary bypass has not been used.

We have determined a 'normal' pattern of change and recovery of memory function after open-heat surgery in our unit. It has been possible to identify. small group of patients in whom the changes $m$ memory function follow a pattern suggesting organ cerebral damage occurring late in the postoperatice period.

Psychiatric sequelae of cardiopulmonary bypass $\rightarrow$ J. M. McKeowN Improved perfusion techniques hage led to a dramatic reduction in the incidence of gross neurological damage after open-heart surgery. An investigation of cerebral impairment should therefore employ more subtle indicators, such as mood disturf bance or deterioration in cognitive function. It is hoped that the observation of such changes will stimalate an investigation of further improvements in bpass techniques.

It was of interest to determine whether psychiatrifc disturbances after cardiopulmonary bypass had sorfe organic basis related to the perfusion technique, su gical procedures, the anaesthetic or to metabolic disturbances or drug administration during the postoperative period. It was also possible that it might have been related to the emotional stress of the operation, especially if there was a previous history of psychiatric illness.

A prospective study was carried out on patients undergoing open-heart operations, and an attempt w\$ made to study a comparable group subjected thoracic surgery.

At a preoperative interview a routine psychiatrix history was taken and the mental state was assessed. Attitudes to surgery and the understanding of the intended operation were determined. Anxiety befote and after operation was determined by means of analogue scale. A battery of psychological tests wa administered preoperatively and again postoperativefy at approximately 48-hour intervals.

Clinical methods of distinguishing organic frot functional psychiatric illness are discussed.

Results indicated that of the small number patients who exhibited psychiatric disturbances th majority had signs of impaired cognitive function ie, an organic disturbance.

Our results seem to indicate that there is still $\frac{T}{\theta}$ small incidence of organic cerebral impairment aftet open-heart surgery. Functional psychiatric illness usually present. Careful observation of such patients in the postoperative period seems to be important. 


\section{Effects of open-heart surgery on intellectual function}

TORKEL ÅBERG and M. KIHLGREN The results from a four-year investigation into the effects of open-heart surgery on intellectual function are discussed. Intellectual function has been assessed (Aberg, 1974) by using a battery of psychometric tests. The effects of changes in the bypass and operative technique cn postoperative function are discussed.

REFERENCE

Áberg, T. (1974). Effect of open heart surgery on intellectual function. Scandinavian Journal of Thoracic and Cardiovascular Surgery. Supplementum 15.

\section{Bronchial hyperreactivity after virus infections of the respiratory tract}

D. W. EMPEY, L. A. I. LAITINEN, L. JACOBS, W. M. GOLD, and J. A. NADEL Bronchial hyperreactivity to inhaled irritants is a characteristic feature of asthma. There is no universally accepted explanation for this phenomenon, but we believe that hyperreactivity follows 'sensitization' of the rapidly adapting superficial airway receptors (irritant receptors). Virus infections of the respiratory tract damage the airway epithelium, expose the irritant receptors, and could thus 'sensitize' them, lowering their threshold for firing (Walsh et al., 1961). We therefore investigated bronchial reactivity and threshold for cough in 16 otherwise normal subjects during colds and after recovery, and 11 normal subjects without colds. In the 11 control subjects inhalation of histamine aerosol $\left(1.6 \%, 10\right.$ breaths) increased airway resistance $\left(\mathbf{R}_{\mathrm{aw}}\right)$ only slightly $(30.5 \pm 5.5 \%$; mean \pm standard error of the mean). During infection baseline $R_{a w}$ was not significantly different from that of the control subjects, but histamine $(1.6 \%, 10$ breaths) produced a much greater response $(218 \pm 54.6 \% ; \mathrm{P}<0.01)$. Bronchial hyperreactivity persisted for several weeks after the resolution of symptoms in most of the subjects, but by seven weeks after the infections the reactivity was normal in all subjects. Isoprenaline $(0.5 \%, 1$ breath) prevented and reversed the increases in $R_{a w}$, indicating that smooth muscle constriction was responsible for the airway narrowing. Atropine sulphate $(0.2 \%, 20$ breaths) also prevented and reversed the effect, indicating that postganglionic cholinergic pathways were involved. The threshold concentration of citric acid that produced cough in subjects with colds was significantly lower than that in the control subjects or in the subjects with colds after recovery $(\mathrm{P}<0.05)$, suggesting that the exaggerated cholinergic response was due to a decreased threshold for stimulation of the airway irritant receptors. We believe that such sensitization of the airway irritant receptors may be an important factor in the development of asthma and other airway diseases.

(Supported in part by NHLI Pulmonary SCOR grant 14201.)

\section{REFERENCE}

Walsh, J. J. et al. (1961). Bronchotracheal response in human influenza. Archives of Internal Medicine, 108, 376-388.

\section{Patterns of onset of severe asthma}

D. Bellamy and J. v. collins Several different mechanisms may cause airways obstruction in asthma, including plugging of the lumen, mucosal swelling, smooth muscle contraction, increased intrathoracic pressure, and change in lung elasticity. In severe exacerbations of asthma the relative importance of each of these mechanisms may vary from one patient to another, especially in relation to the speed of onset of the exacerbation. These differences between patients may be expected to affect the speed of recovery with treatment and should be considered in the design of trials of treatment. Such differences may account for the variation in improvement in arterial hypoxaemia which has been observed in adults (Rebuck and Read, 1971) and children (Pierson et al., 1974).

We have tried to see if there are recognizable patterns of onset of severe asthma in patients presenting to hospital and to relate these patterns to outcome. We are not aware of previous reports of this kind. Details of history and treatment were obtained for 44 episodes of acute asthma in 39 patients at their presentation to hospital, and the results of clinical examination and simple lung function tests were recorded. No attempt was made to influence the decision of the admitting physician or the treatment provided. The mean age of the patients was 33.5 (range 8-73) years and in 29 cases $(66 \%)$ patients were admitted to hospital for treatment. The pattern of onset of the acute illness was related to the duration and severity of the attack and to outcome after treatment. We conclude from this pilot study that in adults rapid onset of severe asthma is uncommon, that infective processes appear the most common precipitating factor, and that airways obstruction is unlikely to be fully reversed until treatment has continued for several days.

\section{REFERENCES}

Pierson, W. E., Bierman, C. W., and Kelley, V. C. (1974). A double blind trial of cortico steroid therapy in status asthmaticus. Pediatrics, 54, 282.

Rebuck, A. S. and Read, J. (1971). Assessment and management of severe asthma. American Journal of Medicine, 51, 788.

\section{Diurnal variation of asthma}

T. J. H. CLARK and M. R. HETZEL Patients with asthma often report that symptoms are worse during the night, and measurements of peak expiratory flow (PEF) are known to show a pronounced diurnal variation in many patients. The coincidence of severe symptoms and a low PEF may account for the observation that death from asthma is liable to occur during the night.

The importance of nocturnal asthma has prompted this study into the factors involved. Patients with asthma have been recruited, and the effects of posture, bedding and sleep were examined. Only sleep seemed to influence the diurnal variation, and as this may have 
resulted from interference with other diurnal rhythms further studies were undertaken of the relationship between wakefulness and diurnal changes in PEF.

Patients with asthma who worked night shifts were given a peak flow meter and recorded expiratory peak flow before going to bed and on rising and noted the clock hour. The diurnal variation of PEF switched from shift to shift and bore a relation to sleep habit rather than clock hour. This switch took place rapidly and was complete by the time the first natural sleep took place on each shift.

The changes in diurnal variation were completed faster than other changes known to occur in diurnal rhythms, and this suggests that the diurnal variation in PEF may be related primarily to fluctuations in wakefulness. Further studies are in progress to see if the relation to wakefulness is simply a manifestation of the timing of treatment which is usually taken when patients are awake.

\section{Bromocriptine in the treatment of intractable asthma}

A. J. NEWMAN TAYLOR, C. SOUTAR, J. SHNEERSON, and M. TURNER-WARWICK A pilot study of bromocriptine, a drug acting directly on dopaminergic receptors, has been undertaken. All of the patients included in this study had disabling asthma which had failed to respond to conventional treatment with steroids and bronchodilators. The drug was given in an initial dose of $2.5 \mathrm{mg}$ per day which was slowly built up to a maintenance dose of $20 \mathrm{mg}$ per day.

Among the patients fulfilling the criteria for inclusion in the study were four who showed regular cyclical increases in airways obstruction either at night or on waking in the morning. Three of this group have shown a sustained improvement in symptoms and functional measurements while on bromocriptine. This has allowed a considerable reduction in steroid dosage and a decrease in these patients' symptomatic bronchodilator requirements. In two of these three, salbutamol spandets taken at night appear to have exerted a synergistic effect with bromocriptine in preventing airways obstruction only while both drugs were used concurrently. In the third successfully treated patient, bromocriptine was temporarily withdrawn because of possible side effects, with immediate recurrence of asthma. The fourth patient of this group has shown no improvement while on treatment.

The encouraging results obtained from this small pilot study suggest the need for a full double-blind trial to evaluate the value of this drug in the treatment of this difficult clinical problem.

\section{Interaction between isoprenaline and aminophylline in asthma}

I. A. CAMPBELl, W. G. MIDDLETON, R. MackeNZIE, M. V. SHOTTER, G. J. R. MCHARDY, and A. B. KAY Beta sympathomimetic drugs and theophyllines are thought to cause bronchodilatation by increasing the concentra- tion of cylic adenosine monophosphate (cyclic AMP) in $\underset{\overrightarrow{2}}{\vec{*}}$ bronchial and bronchiolar smooth muscle, the one by stimulating adenyl cyclase and the other by inhibiting phosphodiesterase. These two types of drug might $\frac{\overline{\bar{N}}}{\bar{D}}$ therefore be expected to act synergistically if given $\frac{\omega}{7}$ together, and there is evidence that this occurs in vitro $\mathbb{\unrhd}$ (Kaliner et al., 1971).

We have studied the effect of inhaled isoprenaline ${ }^{\infty}$ $(0.18 \mathrm{mg})$ and intravenous aminophylline $(250 \mathrm{mg})$ in $\vec{O}$ 38 patients with stable asthma. The aim of the study was to determine whether these drugs, when given to- $\omega$ gether, showed evidence of interaction in terms of their effects on airways obstruction, heart rate, and plasma $x$ levels of cyclic AMP. A factorial design was used in a double-blind, between-patient, placebo-controlled $\vec{A}$ study. Eight patients received placebo, nine isopre- $\vec{p}$ naline, 10 aminophylline, and 11 the combination of isoprenaline and aminophylline. Maximal expiratory을 flow rate (MEFR), maximal flow rate at $50 \%$ forced vital capacity $\left(V_{\max }\right)$, heart rate, and plasma cyclic $\gg$ AMP levels were measured before treatment and at $5,10,20,30,60$, and 120 minutes after treatment.

Analysis of the results showed synergistic interaction on $V \max _{50} 20$ minutes after treatment. At other $\vec{\theta}$ times the interaction on $V \max _{50}$ was additive. On MEFR addition only was demonstrable. Heart rate was increased by both drugs but no interaction was apparent. Plasma cyclic AMP concentrations increased after the administration of either drug and when the $\bar{\partial}$ drugs were given together, the changes running parallel with the changes in airways obstruction, but $\stackrel{\AA}{\varrho}$ interaction was not detected.

The demonstration of synergistic as well as additive $\stackrel{\vec{g}}{\exists}$ effects provides evidence in vivo of the action of these drugs and emphasizes the clinical value of combined bronchodilator therapy.

\section{REFERENCE}

Kaliner, M. A., Orange, R. P., Koopman, W. J., Austen, K. F., and Laraia, P. J. (1971). Cyclic adenosine $3^{\prime} 5^{\prime}-$ monophosphate in $\times$ human lung. Biochemica et Biophysica Acta, 252, 160.

\section{Resistance to beta-adrenergic agonists}

S. T. HOlgate and A. E. TATTERSField Since the introduction of $\beta$-adrenergic agonists as aerosol bron- $\supset$ chodilators it has been suggested that these drugs, $\frac{D}{0}$ when used over a prolonged period, may lead to a state of diminished adrenergic responsiveness or resis- N tance. The evidence for this is based on clinical observations in some asthmatic patients (Van Metre, 1969; ? Reisman, 1970) and animal studies (Conolly et al., స్ట 1971). Recently, several prospective studies have beeno carried out in asthmatic patients and these have not been able to confirm the development of resistance. In view of these conflicting findings we studied a group of normal subjects before and after prolonged administration of a $\beta_{2}$-adrenergic agonist, salbutamol, and $\frac{T}{T}$ can clearly demonstrate the development of resistance $\frac{\text { }}{\mathbb{D}}$ in these subjects.

Specific airway conductance (SGaw) was measured $\stackrel{\mathscr{\Omega}}{\mathbb{Q}}$ in the body plethysmograph and plotted in a dose 
response curve against inhaled salbutamol $(25-400 \mu \mathrm{g})$ in six normal healthy subjects. After several base line runs the subjects took regular inhaled salbutamol, starting at $100 \mu \mathrm{g}$ qid., increasing the dose at weekly intervals to $1600 \mu \mathrm{g}$ daily. At the end of each week the dose response curves to salbutamol were repeated. After the first week there was a progressive reduction in the response to salbutamol and the maximum value of SGaw achieved at the end of each run was progressively less than that achieved during the control run. After four weeks, when the subjects were refractory to salbutamol, the dose response curves were repeated after intravenous hydrocortisone. This restored the salbutamol dose response curve to normal. These studies clearly demonstrate that resistance to $\boldsymbol{\beta}_{\mathbf{2}}$-adrenergic agonists can be induced in normal subjects by prolonged administration of $\beta$ agonists. This technique provides a valuable model for studying pharmacological interactions in vivo in man.

REFERENCES

Conolly, M. E., Davies, D. S., Dollery, C. T., and George, C. F. (1971). Brit. J. Pharmac., 43, 389-399.

Reisman, R. E. (1970). J. Allergy, 46, 162-177.

Van Metre, T. E. (1969). J. Allergy, 43, 101-113.

\section{Cardiorespiratory state after successful septation of} the primitive ventricular heart

R. S. JONES, J. L. WILKINSON, R. ARNOLD, and D. I. HAMILTON Three children aged 5,8 , and 5 years have survived septation of a primitive ventricular heart at the Royal Liverpool Children's Hospital. Two had required banding of the main pulmonary artery and one was severely cyanosed in infancy.

Their cardiorespiratory state has been investigated at intervals of $5 \frac{1}{2}, 1 \frac{1}{2}$, and $1 \frac{1}{2}$ years after septation. The results of cardiac catheterization and assessment of ventilatory function and exercise are presented.

A fourth child died three months after septation of primitive ventricle. The postmortem appearance of the Dacron septum is illustrated.

The clinical follow-up of these children in association with the data presented suggests that this operation is both feasible and desirable in selected cases. The two circulations can be separated, and ventricular pump action is made available to both.

\section{Small left atrial 'tumours'-echocardiographic findings}

T. A. TRAILL, M. G. ST. JOHN SUTTON, A. VENCO, and R. V. GIBSON Echocardiography is established as a reliable means for detecting large left atrial tumours, since they usually interfere with mitral valve function and during diastole reflect a dense mass of echoes from within the mitral valve orifice. Five patients are reported in whom small left atrial masses were demonstrated, which did not give rise to such characteristic echoes.

They presented with clinical features of mitral valve disease, two with suspected and one with proven en- docarditis. In each case there was a dense cluster of echoes from the abnormal structure lying behind the anterior cusp in diastole, moving to and fro between the left atrium and mitral valve orifice during the cardiac cycle, as was demonstrated by M-mode scanning. Movements of the anterior cusp were barely modified.

Only one of the tumours was a myxoma. Two proved to be infective vegetations attached to the chordae tendineae and two were flail posterior cusps, one of which was fused with its chordae and calcified. Accurate identification of the posterior cusp echoes is helpful in distinguishing such small tumours, but precise diagnosis is urgent in order to exclude myxoma, and entails angiography or early surgical exploration.

An in-vitro comparison of the hydraulic characteristics of the Hancock and Björk-Shiley aortic valve replacements

J. T. M. WRIGHT and L. J. TEMPLE In recent years the Björk-Shiley tilting disc valve and the Hancock porcine xenograft valve have become widely used prostheses for aortic valve replacement, and each has its proponents. Aortic valve replacement is usually carried out to correct stenosis or insufficiency, and so the pressure drop, regurgitation, and visualized flow characteristics of a range of these prostheses have been investigated to ascertain their hydraulic effectiveness.

In this study each prosthesis was mounted at the base of a rigid model of the ascending aorta and subjected to sinusoidally varying pulsatile flow from a ventricular shaped piston pump. The stroke displacement was $61.4 \mathrm{ml}$, and the pumping rate varied over the range 60-140 per minute. A three-element hydraulic model represented the impedance of aorta and systemic circulation. The pressure drop across the prosthesis was measured by a differential pressure transducer, whose output was integrated electronically over the systolic part of the simulated cardiac cycle. Regurgitation percentage was measured by comparing gross quantity pumped with net quantity delivered from the aorta.

In the flow visualization study flow patterns were produced by illuminating tracer particles in the test liquid by a thin sheet of light shone through the central axis of the aorta.

The mean systolic pressure drops produced by the Björk-Shiley valves were lower than those of the Hancock valves of similar mounting diameter. However, a patient fitted with a Hancock valve should be able to achieve a useful increase in cardiac output, in response to exercise, before a clinically significant pressure drop results. Neither type of prosthesis produced clinically significant regurgitation.

The flow patterns produced by the Hancock valve were as expected, but with the Björk-Shiley they depended entirely on the orientation of the valve in the aorta. 
Valve replacement with the Björk-Shiley valve: expcrience of 390 patients

M. G. ST. JOHN SUTTON, G. A. H. MILLER, P. OLDERSHAW, and M. PANETH From September 1972 to December 1974, 390 patients underwent valve replacement with use of the Björk-Shiley tilting disc prosthesis. Mean duration of follow-up is now 23.5 (range 12-41) months. Hospital and late mortality was for (1) isolated mitral replacement (150 patients) $5 \cdot 3$ and $10 \%$; (2) isolated aortic replacement (117) 9.4 and $2.5 \%$; (3) combined mitral and aortic replacement (57) 17.5 and $5.3 \%$; (4) mitral replacement with tricuspid repair (30) 10 and $10 \%$; (5) 36 patients had a Björk-Shiley valve combined with other procedures (CAVBG, aortic reconstruction etc.) with hospital and late mortality of 55.5 and $5.5 \%$. Of the 336 early survivors $(86.6 \%), 212$ were maintained on Persantin alone and 126 on warfarin. Thromboembolic complications, including thrombotic obstruction of the prosthesis, were significantly $(\mathrm{P}<0.01)$ more common in the Persantin (28 of $212,13 \%)$ than warfarin (6 of $126,4 \cdot 7 \%$ ) group, were similar whichever valve was replaced, and responsible for 14 of the 26 late deaths $(54 \%)$. The other major complication and cause of late death was paraprosthetic leak $(13,3.8 \%)$. This was due to subacute bacterial endocarditis in seven. Anticoagulation is indicated for all patients with this prosthesis wherever inserted.

\section{A new technique for mitral valve repair: early post- operative results}

L. H. BURR, C. U. KRAYENBUHL. M. G. ST. JOHN SUTTON, and M. PANETH A new technique for the correction of mitral regurgitation has been developed at the Brompton Hospital as part of our policy of conservative surgery for acquired mitral valve disease.

The mitral plication sutures (MPS) were placed in the flexible portion of the mitral annulus as semicircular double purse-string sutures of 2-0 Ethiflex secured over Teflon pledgets, to reinforce the mitral annulus and prevent mitral regurgitation.

With an overall increase in mitral valve surgery from 112 patients in $1974(8.9 \%$ mortality) to 144 patients in $1975(7.6 \%$ mortality), the conservative policy increased reparative mitral valve procedures from seven in 1974 to 89 in 1975, with a concomitant decrease in mitral replacement from 95 to 51 prostheses.

The new MPS technique was used in 67 patients with a hospital mortality of $4.5 \%$. Seven of these patients had unacceptable results at surgery and required immediate prosthetic replacement. Seventeen patients $(28 \%)$ demonstrated mild mitral regurgitation postoperatively, which was not haemodynamically significant. During early follow-up (average 9 months) three patients $(5.0 \%)$ developed significant mitral dysfunction requiring valve replacement.

In the 20 patients who had postoperative echocardiograms, 16 had normal diastolic filling rates, as evidenced by the measurement of rate of change of left ventricular dimension with time (normal 10-20 $\overrightarrow{\overrightarrow{5}}$ $\mathrm{cm} / \mathrm{s}$ ). Two had significant reduction in diastolic fillingo rates, suggesting moderate mitral valve obstruction $\frac{}{O}$ and two had abnormally rapid filling rates, suggesting mitral reflux. The slow ventricular filling rate even in the least satisfactory mitral valve repairs was stilp two to three times greater than occurs with mitrats valve replacement with either Starr-Edwards or BjörkShiley prostheses. Measurement of the diastolic closure rate of the mitral valve postoperatively was unreliable $\vec{\omega}$ in assessing the results of surgery.

Mitral valve repair, with the new mitral plication suture technique, can be performed with low morklity and good early follow-up results.

Surgical management of combined mitral stenosiso
and aortic valve disease D. C. T. WATSON, H. R. MATthEWS, and J. B. MEADE Patients with aortic valve disease requiring aortic $\rightarrow$ valve replacement and coexisting pure mitral stenosise still present a problem of management. Rather than replace the mitral valve we have performed transatrial ${ }^{\circ}$ closed mitral valvotomy at the same time as aortic $\overrightarrow{0}$ valve replacement in 15 patients.

Mean mitral diastolic gradient at catheterization was $12.4 \mathrm{mmHg}$ (range $8-25 \mathrm{mmHg}$ ). Two valveso showed mild calcification and two mild regurgitation. Pulmonary arterial hypertension was present in 13응 patients. The aortic valve disease was stenosis in two, pure regurgitation in four, and mixed lesions in nine. $\stackrel{\unrhd}{\varrho}$ Antegrade mitral valvotomy was performed on bypass $\vec{\Rightarrow}$ with a Tubbs dilator through a left atrial vent site $\frac{0}{3}$ before prosthetic aortic valve replacement. Mean by- $\frac{}{J}$ pass time was $52.3 \mathrm{~min}$ and mean aortic cross clamp time was $36.5 \mathrm{~min}$.

No deaths occurred postoperatively but three patients died at six weeks, 22 months, and 25 months $\frac{\text { 의 }}{9}$ from cerebrovascular accident, anticoagulant com-x plications, and acute left ventricular failure respect- $\dot{0}$ ively. Eleven patients are normally active (mean? follow-up 2 years 3 months); one has evidence of some residual mitral stenosis.

Excision of a mitral valve that would otherwise be응 suitable for closed valvotomy is unjustified. The tech-? nique presented allows retention of a functioning 0 natural valve and significantly reduces operative mortality for a double valve procedure. O Asbestos content of pleural mesothelioma lungs and $\underset{N}{N}$
of the lungs of Merseyside residents

F. WHITWELL Most pleural mesotheliomas are caused by inhalation of asbestos dust, but probably about $\frac{}{\Phi}$ $20 \%$ arise spontaneously. Even when these tumours $\stackrel{\Phi}{+}$ are known to be asbestos-induced, in only about $25 \%$ is there asbestosis in the lungs, though the rest usually ${ }_{0}^{\circ}$

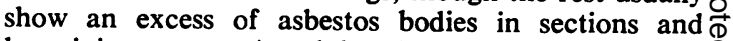
lung juice smears. As adult urban lungs often contain $\frac{\rho}{\Phi}$ asbestos bodies it is useful to have some quantitative $\mathcal{Q}$ method of assessing asbestos dust exposure. 
Absolute asbestos body and fibre counts must include fibres which are ultramicroscopic and require techniques involving extraction, ashing, and electron microscopy. However, if the number of light-visible fibres is proportional to the total fibres present, valuable information can be gained by counting visible fibres, by light microscopy. Gold (1968) used a technique of digesting lung tissue in potash and counting asbestos bodies and fibres in the washed residue in a counting chamber. Ashcroft and Heppleston (1973) improved this technique by more careful washing of the deposit and using phase-contrast microscopy, producing higher counts than those obtained by Gold's method.

In the present investigation Ashcroft and Heppleston's method, slightly modified, has been applied to lungs from 100 pleural mesothelioma patients and to 100 'normal' lungs, the latter being half from hospital necropsies and half from surgical specimens. Occupational histories were obtained in all cases.

In the mesothelioma series over $80 \%$ of lungs contained over 15000 fibres and bodies per gram of dried lung. The cases with fewer fibres usually had no history of asbestos exposure and may represent spontancous pleural mesothelicmas. In the 'normal' series $78 \%$ of lungs showed less than 15000 fibres per gram, and the occupations of those with higher counts were similar to those of mesothelioma patients.

REFERENCES

Gold, C. (1968). The quantitation of asbestos in tissue. J. clin. Path., 21, 537

Ashcroft, T. and Heppleston, A. C. (1973). The optical and electron microscopic determination of pulmonary asbestos fibre concentration and its relation to the human pathological reaction. J. clin. Path., 26, 224.

Patterns of ventilation distribution in health and disease measured by a standardized xenon washout technique

D. SEATON Lung scans using xenon-133 were performed in the supine position in 21 healthy control subjects aged between 19 and 75 , all of whom were non-smokers. The proportion of xenon retained in the lungs 30 seconds after an intravenous injection was found to increase with age.

The same techniques were applied to three groups with no clinical or spirometric evidence of large airways obstruction: (1) eight apparently normal cigarette smoker\$, (2) six non-smoking asbestos workers with clinical, tadiological, and physiological evidence of lung parenchymal asbestosis, and (3) six nonsmoking patients with fibrosing alveolitis.

In the group of smokers, a significantly greater proportion of injected xenon was retained at the lung apices than at the bases, whereas in the group with asbestosis the opposite was found, with greater retention of xenon at the lung bases than at the apices. No such regional differences were observed in the patients with fibrosing alveolitis or in the normal control group.

The abnormal ventilatory pattern in the group of smokers is consistent with the reported distribution of emphysema among cigarette smokers at necropsy (Anderson et al., 1973; Ryder et al., 1971). The pattern observed in the asbestos workers is consistent with histopathological studies which demonstrate that the initial lesions occur around the small airways and are predominant at the lung bases (Wagner, 1965).

\section{REFERENCES}

Anderson, A. E., Alvan, G., and Foraker, A. G. (1973). Centrilobular emphysema and panlobular emphysema: two different diseases. Thorax, 28, 547.

Ryder, R. C., Dunnill, M. S., and Anderson, J. A. (1971). A quantitative study of bronchial mucous gland volume, emphysema and smoking in a necropsy population. Journal of Pathology, 104, 59.

Wagner, J. C. (1965). The sequelae of exposure to asbestos dust. Ann. N.Y. Acad. Sci., 132, 691 .

\section{Serial pulmonary function tests in patients with asbestosis}

M. G. BRITTON and D. T. D. HUGHES The abnormalities of pulmonary function in patients with asbestosis have been well described. Serial studies, particularly of transfer factor, have not been reported, however. A retrospective study of patients referred to the lung function laboratory with a possible diagnosis of asbestosis was made. From all the information available on 199 patients, 48 had definite asbestosis according to the criteria of Parks (1973). Seventeen patients had serial studies over a period of four to 12 years. Seven of these have since died. A further 10 fatal cases had had lung function tests carried out within a year of death.

The mean period following exposure before patients were referred to the laboratory was 32 years. By this time the most constant finding was a reduced transfer factor. In many cases this fall in transfer factor preceded by several years any significant decline in vital capacity. In scme cases both transfer factor and vital capacity were severely impaired when first seen. Four such cases continued to have low values of both parameters which remained constant over periods of up to 12 years.

Death in the majority of cases was due to intervening bronchial carcinoma. This of itself did not alter pulmonary function. This study suggests that lung function tests as such, particularly measurement of transfer factor, were helpful in supporting the diagnosis of asbestosis but were not helpful in prognosis.

REFERENCE

Parks, W. R. (1973) Asbestos-related disorders. British Journal of Diseases of the Chest, 67, 261.

\section{Ten-year follow-up of three patients with beryllium} disease

A. T. AXFORD, J. E. COTES, and J. C. GILSON There is good evidence that exposure to beryllium may result in both acute and chronic pulmonary damage (Andrews et al., 1969), and most cases of beryllium disease arise as a result of occupational exposure (Hasan and Kazemi, 1974).

Three patients with beryllium disease attending the Medical Research Council Pneumoconiosis Unit have 
been observed over a period of 10 years. All were identified in 1964, two from a survey of 130 beryllium workers at a factory manufacturing industrial ceramics, and the third from a smelting plant. The initial findings on this case have been reported previously (Henderson, 1970). In only one case did symptoms develop during the period of exposure, while in all of them the radiographic changes developed after exposure had ceased.

The administration of corticosteroid drugs has resulted in a gratifying clinical improvement, some clearing of the chest radiograph, and return of lung function towards normal: in clinical management the most useful indices have been the transfer factor, the total lung capacity, and the exercise ventilation. The steroids have now been withdrawn in one case and greatly reduced in another without relapse, but it will be shown that the dosage should be assessed critically; premature or too rapid a reduction can have alarming consequences.

REFERENCES

Andrews, J. L., Kazemi, H., and Hardy, H. L. (1969). Patterns of lung dysfunction in chronic beryllium disease. Amer. Rev. resp. Dis., 100, 791-800.

Hasan, F. M. and Kazemi, H. (1974). Chronic beryllium disease; a continuing epidemiological hazard, Chest, 65, 289-293.

Henderson, A. H. (1970). Chronic beryllium disease: a new case following exposure in 1961. Brit. J. Dis. Chest, 64, 169-173.

\section{Late deaths from resection of bronchial carcinoma}

J. R. BELCHER A study has been made of 863 late deaths after resection for bronchial carcinoma. The minimum follow-up period was five years, and 960 patients were studied (360 thoracotomies without resection were done during the same period). The fiveyear survival rate was $26.2 \%$, the 10 -year rate was $17.5 \%$, the 15 -year rate was $6 \%$, and eight out of 210 possible patients survived more than 20 years. Six hundred and ten deaths were due to bronchial carcinoma $(77 \%), 70$ were due to respiratory disease (9\%), 48 were due to coronary thrombosis $(6 \%)$, and 25 were due to other neoplasms $(3 \%)$. The expectation of surviving five years after resection improved at $15 \%$ per year, and of surviving 10 years improved $9 \%$ per year. The late deaths due to bronchial carcinoma as a proportion of those at risk fell in the exponential curve from the day of operation to the 10th year from $31 \%$ to $1.4 \%$. Thirty-four per cent of the deaths occurring after 10 years were due to bronchial carcinoma (a far greater proportion than in the population at large). The second most common cause of death was respiratory disease, and this was related to the extent of resection. Death from other causes occurred in proportions which might have been expected in the age group involved.

Pulmonary necrobiotic rheumatoid nodules without rheumatoid arthritis

C. D. ERAUT, J. A. EVANS, and M. CAPlin Pulmonary necrobiotic rheumatoid nodules are probably the least common of the pulmonary lesions associated with rheumatoid arthritis and are the least controversial since their histology is identical with that of subcutaneous rheumatoid nodules (Turner-Warwick, 1969).

About 50 cases have been reported. In all of these, with one exception, long-standing systemic rheumatoid arthritis preceded the development of pulmonary necrobiotic rheumatoid nodules (Panettiere et al., 1968; Walker and Wright, 1968). A review of the records of the London Chest and Brompton Hospitals has revealed about 25 cases of pulmonary nodules associated with long-standing rheumatoid arthritis. We, however, present here six cases which have the typical features of necrobiotic nodules, including an area of central necrosis surrounded by a palisade of histiocytes, plasma cells, and fibroblasts. A brief account of their clinical, radiological, and histological features is given. In two, pulmonary nodules preceded the appearance of systemic rheumatoid arthritis by six months and 11 years respectively. In four further cases, which have been followed for from four to 26 years, titres of circulating rheumatoid factor have always been normal, and systemic rheumatoid arthritis has not yet appeared.

Attention is drawn to the long latent period which may occur between the development of these nodules and the onset of systemic rheumatoid arthritis. The diagnostic difficulties which may occur if these nodules cavitate is discussed. In our cases, circulating rheumatoid factor has not been present during the latent period, and has appeared only when systemic rheumatoid arthritis has developed.

REFERENCES

Panettiere, F., Chandler, B. F., and Libcke, J. H. (1968). Amer. Rev. resp. Dis., 97, 89-95.

Turner-Warwick, M. (1969). British Journal of Hospital Medicine, 2, 507-513.

Walker, W. C. and Wright, V. (1968). Medicine, 47, 501-520. 